\title{
Environmental Protection through Cleaner Production
}

\author{
Prof. N. A. Patel ${ }^{1}$, Dr. D. K. Parmar ${ }^{2}$, Dr. S. K. Dave ${ }^{3}$ \\ Lecturer, Civil Engineering Dept., BBIT, V.V. Nagar, Gujarat, India ${ }^{1}$ \\ Lecturer, Applied Mechanics Engineering Dept., BBIT, V.V. Nagar, Gujarat, India ${ }^{2}$ \\ HOD, Civil Engineering Dept., BBIT, V.V. Nagar, Gujarat, India ${ }^{3}$
}

\begin{abstract}
Many countries have begun to take initiatives to adopt cleaner production in order to curb pollution and some successes have been achieved. India has been largely an agricultural economy and it has only since early eighties that the industrial sector has almost become at similarity with agriculture. Cleaner Production is an attractive method to challenge environmental problems associated with industrial production and poor material efficiency. Cleaner production (C.P.) provides an important framework for understanding relationship between environment and industrial economy in present industrial system. It also opens up new way of thinking about the evolution of our industrial system in a manner that will help industries, environment, society and thereby human being.
\end{abstract}

Keywords: Cleaner production (C.P.), Environmental Protection, Small and Medium Enterprises (SMEs).

\section{INTRODUCTION}

Countries in Asia have experienced considerable economic growth and the rapid industrialization has led to environmental problems. Many countries have begun to take initiatives to adopt cleaner production in order to curb pollution and some successes have been achieved.

India has been largely an agricultural economy and it has only since early eighties that the industrial sector has almost become at similarity with agriculture. A major feature of the industrial scenario of India has been the growth of Small and Medium Enterprises (SMEs). The major plunge area in Industrial development of India has been the small scale sector.

The purpose was to group the industries on economic scale in suitable sites with facilities of water, transport, electricity, bank, etc. and provide with special arrangement for technical guidance and common infrastructure facilities. All the factors have a direct impact on the environmental approach of the SMEs, which is so far been wholly under assessed. It is estimated that SMEs in India contribute to $65 \%$ of the total industrial pollution.

Cleaner Production is an attractive method to challenge environmental problems associated with industrial production and poor material efficiency. It shows that significant financial saving and environmental improvements can be made by relatively low-cost and direct interventions. This improves the quality of products and minimizes the cost of production, permitting the branch to complete in the global market. Additionally, Cleaner Production also improves the company's public image by highlighting the steps it has taken to protect the environment form pollution.

\section{INDUSTRIALIZATION}

Industrialization refers to a process of transformation in the technology used to produce goods and service. The role of industrialization in the development of country can be investigated as follows ${ }^{[10]}$ :

$>$ Increase in per capita income of people

$>$ Growth in international trade

High level of investment in all sectors

Generation of employment in all regions.

\section{EFFORTS FOR BETTER ENVIRONMENT}

All type of industries use resources of one type or another to produce products or deliver services for meeting requirements of other businesses and communities. In this process, some resources remain unspent, or undesirable products get produced as waste because $100 \%$ conversion or transfer of resources is rarely possible. This waste when discharged to the atmosphere creates pollution. These waste many be solid .liquid waste or Gaseous. The first hand method accepted for solving this problem was "End of Pipe" (EOP) treatment. End-of-pipe (EOP) treatment is any system that processes waste before discharging it to the environment, including waste burning, recycling and chemical treatment.

\section{What is Cleaner Production?}

Cleaner production $(\mathrm{CP})$ is a preventative approach to managing the environmental impacts of business processes and products.[9] CP uses changes in technology, processes, resources or practices to reduce waste, environmental and health risks; minimize environmental damage; use energy and resources more efficiently; increase business profitability and competitiveness; and increase the efficiency of production processes. Cleaner 
production is applicable to all businesses, regardless of size or type.

The concept was developed during the preparation of the Rio Summit as a program of UNEP (United Nations Environmental Program) and UNIDO (United Nations Industrial Development Organization) under the leadership of Jacqueline Aloisi de Larderel, the former Assistant Executive Director of UNEP. Manufacturing in which waste minimization and prevention practices are continuously applied.

These practices include.

$>$ Conservation of raw materials and energy

$>$ Elimination of toxic input and reduction in toxic output

\section{SIX STEP CP METHODOLOGY}

The systematic CP methodology developed under DESIRE project contains is given below[7].

A systematic Methodology for an Effective Cleaner production

\section{STEP 1.}

\section{GETTING STARTED}

Planning and organization of the Cleaner Production audit, including the establishment of a project team, baseline data collection and the selection of the audit focus.

STEP 2.

\section{ANALYSING PROCESS STEPS}

Evaluations of the unit operations relevant to the selected audit focus in order to quantify waste generation, its costs and its causes.

\section{STEP 3.}

\section{GENERATING CLEANER PRODUCTION} OPPORTUNITIES

Development and preliminary selection of workable Cleaner Production opportunities.

STEP 4.

\section{SELECTING CLEANER PRODUCTION} SOLUTIONS

Assessing the technical feasibility, financial viability and environmental desirability of preliminary selected $\mathrm{CP}$ options in order to select feasible CP solutions.

\section{STEP 5. \\ IMPLEMENTING CLEANER PRODUCTION SOLUTIONS}

Actual implementation of the techno-economically viable $\mathrm{CP}$ solutions and monitoring of the results achieved by their implementation.

\section{STEP 6.}

\section{SUSTAINING CLEANER PRODUCTION}

Tools and techniques for sustaining the implemented CP solutions and elaborating the scope in other areas.

\section{CLEANER PRODUCTION ASSESSMENTS}

The Cleaner Production Assessment (CPA) is perhaps the core service a centre can offer an enterprise. A good CPA helps the enterprise in many ways. The benefits of a CPA include:

Identification, characterization and quantification of waste streams and thus environmental and economic assessments of loss of resources (material and energy)

$>$ Identification of easy to implement and low-cost cleaner production options that enterprises can immediately implement; and

Preparation of investment proposals to financing institutions for undertaking medium to high cost cleaner production measures that may require technology or equipment change.

Additional benefits of a CPA include:

> Building a "cleaner production culture" in the company, which is crucial for long-term sustainability;

Helping in the estimation of the potential of cleaner production in the concerned sector and thus in the formation of the basis for sectoral policy reforms; and

> Helping in identifying the technology and skill development needs of the company and sector. In fact, conducting the CPA is an excellent method of building competence of the staff at the centre, as well as the staff in the participating company.

\section{ENVIRONMENTAL BENEFITS}

Benefits of Cleaner Production Application [8]:

$>$ Prevent pollution and environmental degradation through waste minimization efforts, recycling, treatment, and safe waste disposal.

$>$ Supports the principle of environmental preservation in the context of the implementation of Sustainable Development.

$>$ In the long run can increase economic growth through the application of production processes, use of raw materials and energy efficient.

$>$ Preventing or slowing environmental degradation and reduce the exploitation of natural resources through the implementation of waste recycling and the processes that ultimately lead to the conservation of natural resources to achieve Sustainable Development.

> Provide opportunities for economic benefits, because in the net production is pollution prevention strategies at the source (source reduction and recycling in process), which inhibit the formation of waste at an early stage, thereby reducing the investment costs that must be paid for treatment and disposal of waste or environmental improvements

$>$ Strengthen product competitiveness in the global market.

$>$ Improve the image of producers and increasing consumer confidence in the products produced.

$>$ Reducing the level of health hazard and safety 


\section{CONCLUSION}

Cleaner production (C.P.) provides an important framework for understanding relationship between environment and industrial economy in present industrial system. It also opens up new way of thinking about the evolution of our industrial system in a manner that will help industries, environment, society and thereby human being.

It is to be emphasized that above case study only illustrates some positive initiative attitude being taken by some of the small and medium scale industries (SMEs). But what is important is to the cognizance of the typical situation (i.e. Competition, Environmental Problem, Sustainability) prevailing within the industrial sector of the country.

\section{REFERENCES}

[1] Fresner, J., Bürki, T., Sittig, H., Ressourcen effizienz in der Produktion -Kosten senken durch Cleaner Production, ISBN 978-3939707-48-6, Symposion Publishing, 2009.

[2] Gcpc report contribution of gcpc-envis for india's intended nationally determined contribution working towards climate justice 2015

[3] Role of Industrialization in the Economic Development of India

[4] Repole s., Cleaner Production. Esperienze internazionali e proposte per la Toscana, IRPET - Istituto Regionale Programmazione Economica Toscana, 2006.

[5] Tizzi e., marchettini n. Che cos'è lo sviluppo sostenibile?, Donzelli Editore, Roma, 1999

[6] Van berkel r. "Cleaner Production for process industries", Curtin University of Technology, Western Australia, 2000.

[7] www.gcpcenvis.nic.in/CPMethodology.aspx

[8] www.rec-caucasus.org/cp/wp-content/.../Modules-Trainings-Day1.pdf

[9] Websites. http://ic.gujarat.gov.in/?page_id=290334, http://www. thisismyindia.com/gujarat/gujarat-industrial-scenario. html 